\title{
Ang Gabi ng Baconaua
}

\section{Paull Alcoseba Castillo}

\section{University of Santo Tomas}

Mahabang pagtawid sa laot at dilim ang tinatangka ng Baconaua ni Joseph Israel Laban gaya ng mapapansing pagdaan sa kuwadro ng mga bangka sa kalagitnaan ng tubig, at mabagal na pagbagtas ng tauhan dito (Pigura 1). Ang magkahiwalay na pagdaraos ng ritwal para sa mga pinaniniwalaang yumao't hindi na bababalik na mga kaanak ay pagpapakahulugan na ang karimlan ng gabi at karagatan ay kamatayan. Gaya ng ritwal ng paglilibing ng mga sinaunang Filipino na makikita sa mga Manunggul jar, makikita sa ibabaw nito ang paghahatid sa kabilang panig lulan ang bangka. Gayunpaman, ang pagpili na padilimin lalo ang sinematograpiya upang iparamdam na isang hindi natatapos na eklipse ang kabuuan ng pelikula. Ito ang karaniwang iniuugnay sa halimaw na bakunawa na sinasabing kumakain sa buwan at sanhi ng pagkawala nito tuwing eklipse. Tumutugtog mula sa transistor ang dalawang banyagang bersiyon ng pambansang awit ng Filipinas hudyat ng bagong araw ngunit ang imahen ng mga islang ipinatatanaw ng kamera'y sumasalungat sa nadidinig dahil halos walang araw na nagpapaliwanag sa kalupaan.

Bukod sa pagkawala ng liwanag, may iba pang katangiang iniuugnay sa nilalang na bakunawa ang tuwiran at hindi tuwirang ipinamamalas. Dito, pinaniniwalaang ito ang kumukuha sa mga nangangahas na lumusong sa pampang o pumalaot sa pusod ng dagat tulad ng pagkawala ng ama 


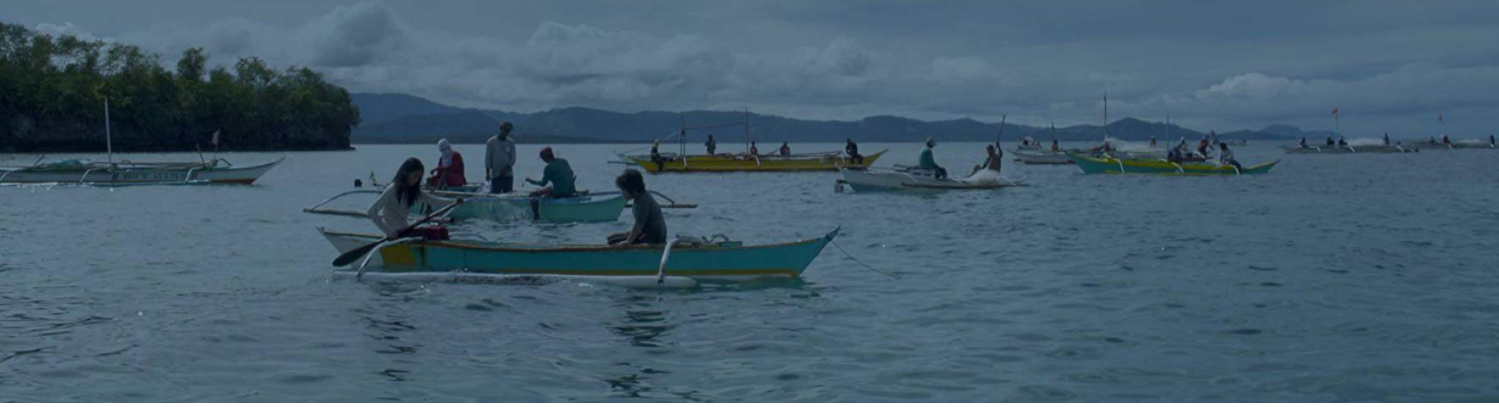

Pig. 1. Karaniwang buhay ng mga taga-isla bago ang mahabang gabi. (Baconaua, dinirhe ni Joseph Israel Laban, One Big Fight Productions at Waning Crescent Arts, 2017)

ng magkakapatid at ang pananakot ng mga bata sa dalampasigan. Para sa mga Marinduqueño rito, bahagi ng kanilang pamumuhay ang paniniwala sa halimaw na nangunguha ng tao na bahagya lamang ipinasisilip ng pelikula, marahil upang mapanatili ang misteryo nito. Nananatili ito sa ilalim ng tubig para hindi basta makita gaya ng aksidente ni Dino (JM Salvado), ang bunso at nag-iisang lalaki sa magkakapatid. Ngunit ang lokal na bakunawa ng lalawigan ay itinutumbas din sa dragon ng kanluran at ng mga Tsino na inilalahad sa pagdating ng dayuhan mulang Tsina.

Sa kabilang panig, nariyan ang buwan na lagi't laging kinakain ng nasabing halimaw, na ayon sa mito'y lumamon din sa dati'y anim na iba pang buwan. Kaya lamang nailigatas ang huli't ikapitong buwan dahil gumawa ng ingay ang mga tao upang itaboy pabalik sa pinagmulan ang bakunawa. At 


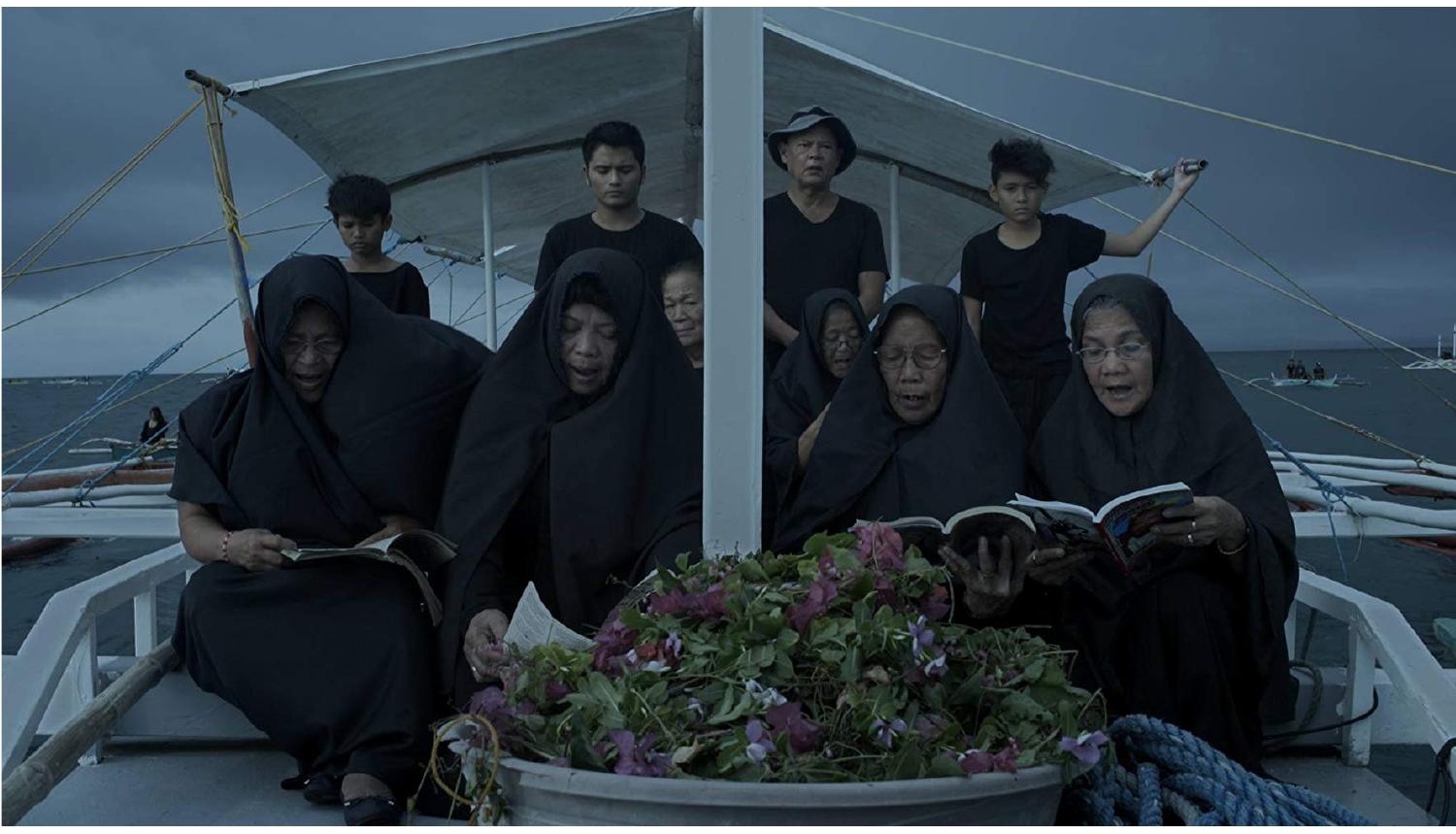

Pig. 2. Ritwal ng paghahatid sa kabilang buhay na di sang-ayon sa Kristiyanismo. (Baconaua, dinirhe ni Joseph Israel Laban, One Big Fight Productions at Waning Crescent Arts, 2017)

gaya ng arketipikong pagtutumbas ng buwan sa babae sa iba't ibang panitikan, ang papel nina Divina (Elora Españo) at Dian (Therese Malvar), ang dalawang supling ng nawawalang ama, ay maaaring makitaan ng katangian ng buwan. Higit pa itong mamalas sa dulong bahagi ng pelikula, sa kabilugan ng buwan, sa sandaling waring nag-iisa na lamang ang panganay, ipinahihiwatig ang pag-ako ng natitirang anak sa tungkuling iniwan ng lumisang ina, nawawalang ama, napaslang na bunso, at suwail na kapatid. Maging ang huling imahen ay naglalarawan ng pagiging isa o pagsasanib ng nanlalaking buwan sa ibabaw ng dagat habang pumapalaot papalapit dito si Divina.

Mula sa katutubong paniniwala, mahahalata ang pag-iral ng konseptong nagmumula sa Kristiyanismo maging sa malay ng mga nasa labas ng sentro ng kapangyarihan (Pigura 2). Ang biglang pagdating ng napakaraming 
mansanas sa dalampasigan ay masamang pangitain para sa ilan sa pamayanan ngunit itinuring na biyaya ng iba. Kung susundin ang depiksiyon ng mga likhang sining na halaw sa Henesis, ang mansanas dito ang prutas na pinagmulan ng pagkakasala't pagkamulat ni Eba, isa ring babae na nagpasya para sa kanilang dalawa ni Adan. Pero dito, mapapansing natutuhan ni Divina ang leksiyon ng kaniyang pagkakasala na pilit niyang ipinababatid sa kapatid na nahulog din sa parehong lalaki na literal at metaporikal na nagpakagat sa ipinagbabawal na bunga.

Higit na makapangyarihan ang dagat rito kaysa sa piniling ipakita ng pelikula at higit dapat na katakutan kaysa sa bakunawa sapagkat sa tubig umiinog ang kabuhayan ng lahat ng mamamayan. Dito nagmumula ang kanilang kakanin sa araw-araw ngunit ito rin ang bumabawi sa mga mahal sa buhay. Dito nila idinaraos ang mga ritwal at ipinauubaya ang naging buhay ng mga yumao gayong ito ang naglayo nang tuluyan sa mga magulang at supling. Dito nagmumula ang biyaya at yamang madali nilang mahahango ngunit dito rin nagmumula ang mga banta mula sa labas. Ang laot ng Baconaua ay dapat kilalanin bilang tauhang kayang maging mapagbigay ngunit marunong bumawi upang pantaying muli ang kalikasan. 


\section{Pagkilala}

Muling nilagda nang may pahintulot ng may-akda mula sa Kung Sine Sine

Lang blog, June 8, 2017, kungsinesinelang.wordpress.com/2017/08/06/ ang-gabi-ng-baconaua/. 